\title{
Enhancing the function of PLGA-collagen scaffold by incorporating TGF- $\beta 1$ loaded PLGA-PEG-PLGA nanoparticles for cartilage tissue engineering using human dental pulp stem cells
}

\section{Parisa Ghandforoushan}

Tabriz University of Medical Sciences

Jalal Hanaee

Tabriz Medical University: Tabriz University of Medical Sciences

\section{Zahra Aghazadeh}

Tabriz University of Medical Sciences

Mohammad Samiei

Tabriz Medical University: Tabriz University of Medical Sciences

Amir Mohammad Navali

Tabriz Medical University: Tabriz University of Medical Sciences

Ali Khatibi

Alzahra University

Soodabeh Davaran ( $\nabla$ s.davaran2018@gmail.com )

Tabriz University of Medical Sciences

\section{Research Article}

Keywords: Nanocomposite hydrogel, Cartilage regeneration, Collagen, Scaffold, Biocompatibility, Tissue engineering

Posted Date: March 7th, 2022

DOI: https://doi.org/10.21203/rs.3.rs-1375971/v1

License: (c) (i) This work is licensed under a Creative Commons Attribution 4.0 International License. Read Full License 


\section{Abstract}

Researchers have scrutinized cartilage tissue regeneration to handle the deficiency of cartilage restoration capacity. This investigation proposed to compose an innovative nanocomposite biomaterial that enhances growth factor delivery to the injured cartilage site. Here, we describe the design and development of the biocompatible PLGA-collagen / PLGA-PEG-PLGA nanocomposite scaffold containing TGF- $\beta 1$. PLGA-PEG-PLGA nanoparticles were employed as a delivery system embedding TGF- $\beta 1$ as an articular cartilage repair therapeutic agent. This study evaluates various physicochemical aspects of fabricated scaffolds by ${ }^{1}$ HNMR, FT-IR, SEM, BET, and DLS methods. The physicochemical features of the developed scaffolds, including porosity, density, degradation, swelling ratio, mechanical properties, morphologies, BET, ELIZA, and cytotoxicity were assessed. SEM images displayed suitable cell adhesion and distribution of hDPSCs throughout the scaffolds. The cell viability was investigated with the MTT test. In real-time PCR testing, the expression of Sox-9, collagen type II, and aggrecan genes was monitored. According to the results, h-DPSCs exhibited high adhesion, proliferation, and differentiation on PLGA-collagen/PLGA-PEG-PLGA-TGF- $\beta 1$ hydrogels compared to the control groups. RT-PCR assay data displayed that TGF- $\beta 1$ loaded PLGA-PEG-PLGA nanoparticles puts forward chondroblast differentiation in hDPSCs through the expression of chondrogenic genes. Due to its potential for the growth and differentiation of hDPSCc, PLGA-collagen/PLGA-PEG-PLGA-TGF- $\beta 1$ hydrogel is likely to be a suitable biomaterial for cartilage regeneration.

\section{Introduction}

Articular cartilage is an elastic tissue that covers and supports the joint's bone surface and enables painless motion possible $[1,2]$. Osteoarthritis $(\mathrm{OA})$ is the most common musculoskeletal disorder, results from a defect in the articular cartilage, and is known as the world's leading cause of pain and handicap. $\mathrm{OA}$ significantly lessens the quality of patients' lives and disrupts their daily lives [3]. Currently, despite the availability of conventional treatments, applicable and appropriate long-term remedies for cartilage imperfections are still required. Several methods have been proposed for replacing cartilage injuries, such as autographs, allografts, xenografts which have limitations in function and efficacy [4]. The repair or replacement of tissue with a synthetic substitute is limited to situations in which surgical procedures and implants have been successful [5]. The limited regeneration capacity of articular cartilage has led to the maturation of cell-based tissue engineering approaches such as autologous implantation of chondrocytes [6].

Tissue engineering path with proper biomaterials has grown a matter of imposing interest. The objective of the tissue engineering strategy is to restore the defected tissue. The requirement for tissue engineering is the employment of temporary 3-D structures in combination with different types of cells and growth factors. Their function is accomplished by filling the defect area, imitating the extracellular matrix (ECM), supporting the cells, and promoting tissue restoration [7]. Cartilage tissue has a unique ability to change its structure and features due to the aggregation of proteoglycans and interstitial fluid flow. The fabrication and development of a scaffold with mechanical properties corresponding to native cartilage 
tissue is, therefore, an essential and challenging task [8,9]. In this context, human dental pulp stem cells (hDPSCs) have been proven as an effective cell source in regenerative medicine due to their multipotential capabilities, donor accessibility, and low cost [10]. hDPSCs display the ability to differentiate into several lines and chondrocytes in particular [11].

3D scaffolds are crucial platforms for supporting cell proliferation, differentiation, and function in tissue regeneration. Scaffolds are described as 3D porous biomaterials which can regulate cell behavior as well as deposition of extracellular matrix (ECM) [12]. These structures should be able to gradually degrade and replace cells with reconstructed tissues while maintaining the structural characteristics of the tissues [13]. Many studies on various scaffolds, biomaterials, and in vivo models have been carried out so far [14]. Over the past two decades, novel hydrogels have been introduced to clinical centers with relatively different compositions and structures that lead to specific properties that have extensively broad use in medicine and pharmacy [15]. Hydrogels are widely used as a depot in targeted regenerative medicine due to their tunable network features, biocompatibility, and high water content. Hydrogels are a favorable biomaterial for cartilage tissue restoration from naturally derived materials to synthetically derived materials $[16,17]$.

Naturally derived biomaterials, like collagen, are assumed as appropriate scaffolds for tissue restoration due to their acceptable biocompatibility. Researchers have observed that collagen-based hydrogels have good biological properties. Consequently, they are widely used in regenerative medicine as restorative materials, in particular in cartilage tissue engineering, and for the delivery of bioactive growth factors. Collagen holds an inherent tendency to promote cell adhesion and induce ECM. Collagen-based hydrogels have been revealed to produce appropriate conditions to keep the encapsulated chondrocyte phenotype [18]. In contrast, there are still some practical problems; the problem of controlling in-vivo degradation, low seed yield efficiency, the toxicity of degradation products due to scaffold degradation, and poor mechanical properties of natural tissue [19]. Collagen-based hydrogels demonstrate weaker mechanical properties than the neighboring tissue when implanted and degrade too quickly compared with tissue regeneration [20]. To overcome collagen constraints, composite collagen scaffolds with other materials such as silk fibroin/hyaluronic acid [21], chitosan [22], and bioactive glass [23] were studied for the construction of cartilage tissue scaffolds. Collagen and synthetic polymers such as polylactic acid (PLA), poly (lactic-co-glycolic acid) glycolic acid (PLGA), and poly (囚-caprolactone) were extensively studied for tissue engineering [24]. In addition, it has been shown that the merging of mechanically sturdy synthetic polymer support with mechanically not-sturdy collagen sponges combines the benefits of synthetic polymers and collagen. The composite scaffolds exhibit high mechanical features, efficient cellto-cell interaction, and a high tissue engineering potential.

On the other hand, a principal disadvantage of synthetic polymers like PGA, PLA, and PLGA is that they have no specific biological functions. Such synthetic polymers must be functionalized using bioactive molecules or biological motifs to promote cell adhesion and induce matrix production. PLGA has hydrolyzable ester links that are degraded in a mammal's subcutaneous layer [25]. Notably, hydrogels such as PLGA-PEG-PLGA can release entrapped drugs or growth factors in a sustained manner at the site 
of interest [26,27]. This strategy generally is performed to circumvent the burst release of growth factors or drugs [28]. Notwithstanding the progress in composite biomaterials, the grand challenge is to increase chondroinductive capacity, as the regenerative stimulation of cartilage defects is very limited by the scaffolds themselves [29]. Incorporating cell growth factors within 3D scaffolds is a solution to this problem [30].

The inclusion of biomolecules and growth factors (GFs), such as dexamethasone, ascorbate, TGF- $\beta 1$, and TGF- $\beta 3$, promised to facilitate cartilage regeneration [31, 32]. Among various GFs, transforming growth factor-beta 1 (TGF- $\beta 1$ ) is assumed to be an efficient agent for inducing chondrogenesis [33].

The objective of this research was to fabricate biocompatible and biodegradable PLGA-collagen/ PLGAPEG-PLGA-TGF- $\beta 1$ nanocomposite hydrogel using the freeze-drying method. Through investigating the expression of Sox-9, type II collagen, and aggrecan, nanocomposite function for chondrogenic differentiation in the presence of hDPSCs was studied.

The findings revealed that PLGA-collagen/ PLGA-PEG-PLGA-TGF- $\beta 1$ can be utilized as a supportive platform to support hDPSCs differentiation by implementing specific physio-chemical features. The chondrogenic potential of PLGA-collagen/ PLGA-PEG-PLGA-TGF- $\beta 1$ was improved when hDPSCs were cultured in the presence of TGF- $\beta 1$.

\section{Materials And Methods}

\section{Materials}

Glycolide and ${ }_{D-L}$ Lactide, and were purchased from Aldrich Chemical Co. (St. Louis, MO, USA).

Phosphate buffered saline (PBS), Stannous 2-ethyl hexanoate (Sn (Oct) $)_{2}$ ), and PBS tablets were prepared from Sigma Aldrich. TGF- $\beta 1$ was obtained from Abcam. TGF- $\beta 1$ Enzyme-Linked Immunosorbent Assay (ELISA) kit was purchase from (Karmaniaparsgene, Iran)). Dulbecco's modified Eagle's medium (DMEM) high glucose, trypsin - EDTA, and fetal bovine serum (FBS) were purchased from Gibco. Lyophilized bovine collagen was gifted from Sahand industrial University (Iran).

\section{Methods}

\section{Preparation of PLGA-PEG-PLGA-TGF- $\beta 1$ copolymer}

PLGA-PEG-PLGA copolymer was prepared by the ring-opening polymerization process. TGF- $\beta 1$-Loaded PLGA-PEG-PLGA copolymer was constructed via the double emulsion method. All the synthesis details have been mentioned in our recently published paper [34].

\section{Synthesis of PLGA-Collagen/PLGA-PEG-PLGA-TGF- $\beta 1$ porous scaffold}

The three-dimensional nanocomposite scaffolds produced through the Freeze-Drying method have mechanical stability suitable for application in cartilage tissue restoration [35]. PLGA-collagen scaffolds were fabricated employing glutaraldehyde as a cross-linking agent. In summary, an aqueous collagen 
solution $(0.5 \% \mathrm{w} / \mathrm{v})$ was composed following dissolving bovine collagen in $1 \%$ acetic acid. Then, the collagen solution was kept at $4^{\circ} \mathrm{C}$.

PLGA with molar ratio LA /GA: $3 / 1$ was dissolved in 1,4-dioxane. Then the collagen solution $(\mathrm{pH}=3.2$, $0.5 \%$ ) was mixed with PLGA solution under stirring at $4^{\circ} \mathrm{C}$. To form PLGA-collagen scaffolds, the solutions were poured into a 6-well plate ( $1 \mathrm{ml} /$ well), and freeze-dried (Telstar) for 48 hours.

TGF $\beta 1$-loaded nanoparticles ( $10 \mathrm{mg} / \mathrm{mL}$ TGF $\beta 1$ concentration) were added to the PLGA-collagen solution, covered, and stirred overnight. The PLGA-collagen /PLGA-PEG-PLGA-TGF $\beta 1$ composite sponges were then placed in a sealed plate containing saturated glutaraldehyde vapor with an aqueous solution of $25 \%$ glutaraldehyde at $37^{\circ} \mathrm{C}$ for $4 \mathrm{~h}$.

The cross-linked scaffolds were immersed in $0.1 \mathrm{M}$ aqueous glycine solution to remove unreacted glutaraldehyde. Finally, they were washed with deionized water, and later freeze-dried for 48 hours. Figure 2A depicts the fabricated PLGA-collagen scaffold.

\section{Sterilization of the scaffolds}

Scaffolds were sterilized by being immersed in $70 \%$ ethanol. All scaffolds were then irradiated with ultraviolet light (UV) for 30 minutes. In the next step, the scaffold was rinsed several times with sterile phosphate buffer saline (PBS) under a laminar flow hood to exclude ethanol before incubation in DMEM for one night at $37^{\circ} \mathrm{C}$. The prepared scaffolds were seeded immediately after sterilization; for all experiments.

\section{PLGA-PEG-PLGA nanoparticles' characterization}

The chemical configuration of the synthesized PLGA-PEG-PLGA, was verified by ${ }^{1} \mathrm{H}-\mathrm{NMR}$. This characterization was recorded using a Bruker Avance $400 \mathrm{MHZ}$ spectrometer. The standard solvent in this assay was $\mathrm{CDCl}_{3}$.

The infrared absorption spectrum of PLGA-PEG-PLGA nanoparticles was analyzed using an ATR-FTIR (BRUKER, Tensor 27) spectrometer. Absorbance spectrum was recorded in the range of 4,000 to $450 \mathrm{~cm}^{-}$ 1.

The surface morphology of the samples was evaluated at an accelerating voltage of $15 \mathrm{kV}$ using field emission scanning electron microscopy (FESEM; Sigma VP, ZEISS, Germany). For this purpose, the freezedried PLGA-PEG-PLGA hydrogels were coated with gold before the scanning.

Size distribution of the PLGA-PEG-PLGA nanoparticles was evaluated by the dynamic light scattering (DLS) method.

\section{PLGA-collagen copolymer's characterization}

\section{FT-IR}


In order to ensure the presence of collagen in the scaffolds and chemical analysis of the scaffolds, ATRFTIR (BRUKER, Tensor 27) spectroscopy of freeze-dried composite scaffolds ranging from 450 to 4000 $\mathrm{cm}^{-1}$ was carried out.

\section{Scaffold textural analysis by SEM}

The morphologies of collagen, PLGA-collagen, and PLGA-collagen/PLGA-PEG-PLGA-TGF- $\beta 1$ scaffolds were determined using SEM. ImageJ software was applied to estimate the average pore sizes of each prepared porous scaffold.

\section{Porosity and density features of the hydrogels}

The porosity $(\varangle)$ of the sponges was measured using the liquid displacement method [36]. Each sponge was immersed 10 minutes before measurement in $5 \mathrm{~mL}\left(\mathrm{~V}_{1}\right)$ of ethanol (Sigma, 96\%). The total volume was $V_{2}$, including the sponge immersed (ethanol + impregnated scaffold). The ethanol saturated sponge was then removed, indicating the remaining volume of ethanol as $V_{3}$. The following equation calculated the porosity of the samples:

Porosity $(\%)=\frac{V 1-V 3}{V 2-V 3} \times 100 \%$

$V_{1}$ is the initial volume of ethanol, $V_{2}$ is the volume after the scaffolds are immersed, and $V_{3}$ is the volume of ethanol after the scaffold has been removed. To obtain mean values, triplicate measurements were performed. The density parameter of the prepared scaffolds was calculated from the below equation:

$$
\text { Density }=\frac{V 1-V 3}{V 2-V 3}
$$

\section{Swelling study}

In the physiological environment, the swelling behavior of the manufactured scaffolds was measured. The same size $(1 \mathrm{~cm} \times 1 \mathrm{~cm})$ weighted $W_{d}$ dry lyophilized composite specimens were immersed in the PBS, at the temperature of $37^{\circ} \mathrm{C}$ for respective time intervals $(24,48,72,96 \mathrm{~h})$. Then, the samples were taken out, and two sheets of paper were placed between the wet samples to remove surface water and weighed $\mathrm{W}_{\mathrm{s}}$. The swelling of the scaffold was calculated by the following equation:

Swelling $(\%)=\frac{W s-W d}{W d} \times 100 \%$

Where $\mathrm{W}_{\mathrm{s}}$ refers to the initial weight before immersion of the sample and Wd refers to the weight after sample drying. Four distinct samples were examined for swelling evaluation.

\section{Degradation analysis}


The degradation behavior of structures holds a critical function in the successful design of tissue engineering scaffolds and the development of new tissue. Degradation behaviors of collagen, PLGA-PEGPLGA, PLGA-collagen, and PLGA-collagen/PLGA-PEG-PLGA hydrogels were systematically investigated at $37^{\circ} \mathrm{C}$ for up to 3 weeks in PBS solution.

To evaluate the degradation rate of the hydrogels three samples with $1 \mathrm{~cm}^{2}$ sizes were weighed correctly for each soaking time $\left(\mathrm{W}_{0}\right)$. Thereafter, a $5.0 \mathrm{~mL}$ PBS solution $(1 \mathrm{M}, \mathrm{pH}=7.4)$ was added to each composite sample in the test tube and incubated at $37^{\circ} \mathrm{C}$ for 28 days in a sterile condition. The PBS solution was refreshed every 3 days. The hydrogels have been sampled at various times intervals $(3,7$, 14 , and 21 days), and the remaining solid content was freeze-dried. After lyophilization for $72 \mathrm{~h}$, the samples were again weighed $\left(\mathrm{W}_{\mathrm{t}}\right)$.

The weight loss ratio of degradation was computed utilizing the following equation:

Weight Loss $(\%)=\frac{W 0-W t}{W 0} \times 100$

\section{Release profiles}

In vitro release profiles of the growth factor from the scaffolds were investigated for 3 weeks. In this regard, $5 \mathrm{mg}$ of each hybrid scaffold containing TGF- $\beta 1$ was dissolved in $500 \mu \mathrm{l}(\mathrm{pH}=7.4,0.2 \mathrm{M})$ of fresh phosphate buffer saline (PBS). Afterward, the samples were placed under constant agitation in the shaking water bath $(100 \mathrm{rpm})$ for 3 hours at $37^{\circ} \mathrm{C}$. The release medium has been replaced by the same amount of fresh buffer every 2 days for 21 days. At determined time points, scaffold specimens were centrifuged at 12,000 rpm for 12 minutes. The supernatant was used for cumulative percentage release finding of TGF- $\beta 1$ protein expression by the commercial TGF- $\beta 1$ Enzyme-linked Immunosorbent Assay (ELISA) Kit (Karmaniaparsgene, Iran). This study was performed in triplicate.

\section{Mechanical properties}

Mechanical features of PLGA-collagen and PLGA-collagen/PLGA-PEG-PLGA hydrogels were investigated employing Zwick tensile testing (Z010, Zwick/Roell, and Ulm, Germany) machine.

For this purpose, PLGA-collagen and PLGA-collagen/PLGA-PEG-PLGA specimens with a size of $1 \mathrm{~cm} \times$ $2 \mathrm{~cm}$ were prepared and attached to the machine. They were immersed for 1 hour in PBS to have hydrated specimens. A $10 \mathrm{~N}$ load was applied at a constant speed of $5 \mathrm{~mm} / \mathrm{min}$. The test was repeated three times in wet conditions (soaking for $1 \mathrm{~h}$ in PBS, $\mathrm{pH}=7.4$ ), and the averages were recorded. Young's modulus parameters were obtained from the initial slope of strain-stress curves.

\section{BET assay}

The specific surface area and porosity of the PLGA-collagen hybrid composites and PLGA-collagen/ PLGA-PEG-PLGA-TGF $\beta 1$ nanocomposites were evaluated using the Brunauer-Emmett-Teller method 
(BET). The Quantachrome NOVA Automated Gas Sorption System, Graz, Austria, was operated for this assay.

\section{In vitro cell culture studies}

Human dental pulp stem cells (hDPSCs) have been isolated, as previously mentioned [37]. All scaffolds were immersed within $70 \%$ EtOH solution for 2 hours. The scaffolds were subsequently immersed in DMEM; containing $1 \%$ penicillin/streptomycin antibiotics and $10 \%$ fetal bovine serum (FBS, Gibco) as the culture media. The plates were incubated for $72 \mathrm{~h}$ before cell seeding to be completely soaked with media.

In this study, human DPSC (passage 4) was cultured in 2 flasks for 10 days to obtain 2,000,000 cells per flask. The hDPSCs were washed with PBS when $80-90 \%$ confluency was reached, detached with $0.05 \%$ trypsin containing $1 \mathrm{mM}$ EDTA.

Afterward, $300 \mu \mathrm{L}$ of media containing a density of $6 \times 10^{4}$ cells were added to each scaffold. hDPSCs could attach to samples. Subsequently, an additional culture medium was flowed into the wells to cover the scaffolds. The cell-seeded scaffolds have incubated with $5 \% \mathrm{CO}_{2}$ in an incubator for 2 days.

\section{Chondrogenic media supplements}

The chondrogen media contained DMEM, and bovine serum albumin, $2 \% \mathrm{FBS}$, ascorbic acid (50 $\mu \mathrm{g} / \mathrm{mL})$, 1X-ITS, streptomycin $(100 \mu \mathrm{g} / \mathrm{mL})$, penicillin $(100 \mathrm{U} / \mathrm{mL})$, and $100 \mathrm{nM}$ dexamethasone. Every 5 days, cell culture media was changed.

\section{Cell attachment analysis}

The adhesion of the hDPSCs to the porous PLGA-collagen/PLGA-PEG-PLGA hydrogels were evaluated via FESEM. In brief, after cell culture (14 days), cell-laden hydrogels were fixed in $2.5 \%$ glutaraldehyde at $37^{\circ}$ $\mathrm{C}$ and were dehydrated in a graded ethanol series. Lastly, they were coated by gold layer.

\section{Cytotoxic assay (MTT)}

MTT assay was applied to assess the cell proliferation and viability of hDPSCs on nanocomposite scaffolds [38]. The sterilized scaffolds by $70 \%$ ethanol and UV irradiation were placed in sterile 96 -well plates. The hDPSCs (cell density $2 \times 10^{4}$ cells/well) were seeded on collagen, PLGA, PLGA-collagen, PLGAPEG-PLGA, and PLGA-collagen/ PLGA-PEG-PLGA nanocomposite scaffolds. Then they were incubated in $200 \mu \mathrm{L}$ normal culture medium. After 3,7 , and 14 days of the incubation, the cell medium was removed from each well, following, $50 \mu \mathrm{MTT}$ solution $(3 \mathrm{mg} / \mathrm{mL}$ in PBS $(\mathrm{pH}=7.4)$ ), was added and the cells were incubated at $37^{\circ} \mathrm{C}$ for 3 hours under $5 \% \mathrm{CO}_{2}$. The MTT solution was discarded; subsequently, DMSO was gently pipetted to each well to dissolve the formosan crystals. The h-DPSCs seeded in the culture plates containing DMEM without the scaffolds were regarded as the control group. 


\section{Alcian blue Staining}

Alcian blue assay was accomplished to evaluate the formation of proteoglycans, which is an essential process in chondrogenesis. The culture medium was aspirated off (14th day), and then cell-seeded scaffolds were rinsed twice with PBS. Later, $4 \%$ paraformaldehyde was added to each of the wells. The cells were fixed at room temperature for 30 minutes. Then, a 1\% Alcian blue solution was applied. The plates were agitated lightly for $30 \mathrm{~min}$ at $25^{\circ} \mathrm{C}$. The Alcian blue solution was discarded from wells at next stage, and the stained cells were washed twice with distilled water. Finally, an inverted light microscope was utilized to observe the stained cells within the scaffolds.

\section{Chondrogenic differentiation of DPSCs}

The expression of cartilaginous genes including Sox-9, type-II collagen, and aggrecan within composite scaffolds was evaluated by real-time polymerase chain reaction (RT-PCR). To investigate chondrogenic differentiation, h-DPSCs were seeded on each scaffold ( $2 \times 10^{4}$ cells/scaffold) and grown for 21 days. As an internal control, GAPDH was applied. The primers used for RT-PCT are listed (Table 1) [39].

Table 1

The applied primers in the real-time RT-PCR analysis

\begin{tabular}{|llll|}
\hline Gene & Sequence & $\left.\mathrm{T}_{\mathbf{M}}{ }^{\circ} \mathrm{C}\right)$ \\
\hline Type-ll collagen & F: 5'-CGTCTACCCCAATCCAGCAAA-3' & $60^{\circ} \mathrm{C}$ \\
& R: 5'-AGCAGGCGTAGGAAGGTCAT-3' & \\
Aggrecan & F: 5'-CCATCTCTACACGCTACACCC-3' & $60^{\circ} \mathrm{C}$ \\
& R: 5'-TTGTCTCCATAGCAGCCTTCC-3' & \\
Sox9 & F: 5'-CACACTCCTCCTCCGGCATGA-3' & $60^{\circ} \mathrm{C}$ \\
& R: 5'-GCGGAAGTCGATAGGGGGCT-3' & \\
GAPDH & F: 5'-AGCCAAAAGGGTCATCATCTCT-3' & $60^{\circ} \mathrm{C}$ \\
& R: 5'-AGTCCTTCCACGATACCAAAGT-3' & \\
\hline Statistical analysis & &
\end{tabular}

All values are expressed as the mean \pm standard deviation (SD). Data analysis was accomplished by GraphPad Prism (version 7) and a one-way ANOVA assay. The $p$ values below $0.05(p \leq 0.05)$ were assumed statistically significant.

\section{Results And Discussion}

\section{PLGA-PEG-PLGA copolymer characterization}


Figure 1A displays the PLGA-PEG-PLGA triblock copolymer ${ }^{1} \mathrm{H}-\mathrm{NMR}$ spectrum (LA/GA = 2.4/1), including its functional groups. This spectrum verified the presence of PLGA-PEG-PLGA copolymer composed of polyethylene glycol (PEG), lactic acid (LA), and glycolic acid (GA). Table 2 describes the chemical shifts of each functional group present in the PLGA-PEG-PLGA.

Table 2

Chemical shifts obtained from the ${ }^{1} \mathrm{H}-\mathrm{NMR}$ spectrum of PLGA-PEG-PLGA copolymer. Not applicable $=\mathrm{N} / \mathrm{A}$

\begin{tabular}{|llll|}
\hline Functional group & $\mathbf{C H}$ & $\mathbf{C H}_{2}$ & $\mathbf{C H}_{3}$ \\
\hline Lactic acid $\sigma(\mathrm{ppm})$ & 5.2 & N/A & 1.65 \\
\hline Glycolic acid $\sigma(\mathrm{ppm})$ & 5.08 & 4.33 & N/A \\
\hline Ethylene glycol $\sigma(\mathrm{ppm})$ & $\mathrm{N} / \mathrm{A}$ & $3.64,4.16$ & N/A \\
\hline
\end{tabular}

The nature of copolymer PLGA-PEG-PLGA was evaluated by ATR-FTIR. As shown in Fig. 1B, the copolymer's FT-IR spectrum has been verified the presence of functional groups in the nanocomposite matrix. The relative wavenumbers of functional groups are categorized in Table 3.

Table 3

IR characterization of the PLGA-PEG - PLGA triblock copolymer

\begin{tabular}{|lll|}
\hline Copolymer & IR bands $\left(\mathbf{c m}^{-1}\right)$ & Functional groups \\
\hline PLGA-PEG-PLGA & 2871,2941 & $\mathrm{CH}_{2}, \mathrm{CH}_{3}$ \\
\cline { 2 - 3 } & 1729 & $\mathrm{C}=$ O from ester band \\
& 1094 & C-O-C from PEG \\
& 2941 & C-H from PEG \\
\hline
\end{tabular}

Utilizing field emission scanning electron microscope (FESEM), the surface morphology and the dimensions of the PLGA-PEG-PLGA nanoparticles were analyzed. The SEM images (Fig. 1C) showed the structure of PLGA-PEG-PLGA nanoparticles with a size dimension below $100 \mathrm{~nm}$. The average nanoparticles size after encapsulation was below $100 \mathrm{~nm}$. PLGA-PEG-PLGA nanoparticles hold a spherical configuration as well.

DLS measurements demonstrate the size distribution of the PLGA-PEG-PLGA nanoparticles. As shown in (Fig. 1D), PLGA-PEG-PLGA nanoparticles made by the freeze-drying process were well dispersed with average dimensions between $80-100 \mathrm{~nm}$.

\section{PLGA-collagen characterization}

FTIR analysis provides information on functional groups within the molecule structure. ATR-FTIR analysis was carried out to investigate the chemical interactions of different functional groups in the scaffolds. Figure 2B shows the PLGA, collagen, and PLGA-collagen hybrid copolymer FT-IR spectra. The collagen 
spectrum pictures absorption bands at 1652, 1545, 1246, and $3309 \mathrm{~cm}^{-1}$ which symbolize amide I, II, III, and amide $A$, respectively [40].

The typical absorption bands of ester in the PLGA structure appeared at $1088-1232 \mathrm{~cm}^{-1}$. Also, amide I peaks can be observed in $3336 \mathrm{~cm}^{-1}$. The spectral range between 1540 and $1550 \mathrm{~cm}^{-1}$ corresponds to amide II.

\section{Morphology analysis of the scaffolds}

Cartilage tissue engineering has evolved from simple materials to complex materials with distinct porosity, surface properties, and the ability to provide biological agents. High porosity and porous structure are critical for tissue regeneration because they can provide a three-dimensional microenvironment suitable for cell penetration and support nutrients/waste exchange between the scaffold and its environment. In this regard, the surface morphology and pore size of the scaffolds were verified by field emission scanning electron microscope (FESEM). We utilized the freeze-drying process to manufacture 3D porous hydrogel scaffolds.

Figure 3 displays SEM micrographs of collagen (Fig. 3A), PLGA-collagen (Fig. 3B), and PLGAcollagen/PLGA-PEG-PLGA-TGFß1 (Fig. 3C) composites. SEM Images revealed that hydrogels have porous structures interconnected. Obtained results confirmed that during the freeze-drying process a pores structure was established throughout the structures. As shown in (Fig. 3C), with the embedding of PLGAPEG-PLGA nanoparticles, the pore size of the PLGA-collagen scaffolds was decreased. Figure 3D demonstrated the average pore size of the prepared scaffolds, determined by ImageJ. The obtained average pore sizes were in accordance with the porosity degree of each hydrogel. According to the findings of the investigation, $100-500 \mu \mathrm{m}$ pore size would be proper to support better ECM production and gene expression that leads to chondrogenesis [41, 42].

\section{Porosity and density evaluations}

Apart from pore size, porosity is one of the most significant growth and proliferation factors for cell growth due to nutrient and oxygen transfer. On the other hand, the porosity provides an appropriate interaction between cells and the scaffold [43]. Based on our results, as shown in Fig. 4A, the porosities of collagen (80\%), PLGA-PEG-PLGA (78.33\%), and PLGA-collagen (61.33\%) are higher than the nanocomposite PLGA-collagen/PLGA-PEG-PLGA scaffolds (42.61\%). With embedding the PLGA-PEGPLGA nanoparticles, the porosity degree of PLGA-collagen scaffolds was decreased by about $20 \%$. The porosity of all scaffolds was found to be sufficiently high values for cell growth support, as well as metabolite diffusion for hDPSCs $[44,45]$.

Regularly, strives to increase density leads to a reduction in porosity. The higher scaffold densities provide better mechanical durability, whereas high porosity provides a proper physiological environment for the cultured cells and weakens mechanical strength. Therefore, a balance between density and porosity parameters is vital. Figure 4B displays the density of collagen, PLGA-PEG-PLGA, PLGA-collagen, 
and PLGA-collagen/PLGA-PEG-PLGA scaffolds. Based on these observations, prepared nanocomposite scaffolds could provide an efficient matrix for cartilage tissue restoration.

\section{Swelling evaluation}

The absorption of the body fluids and retention of them are fundamental features of hydrogels. The swelling characteristic of the scaffold is imperative, as water is $70-85 \%$ of the weight of cartilage tissues. The swelling study results were performed during $96 \mathrm{~h}$, and the results are shown in Fig. 5A. In collagen hydrogels, a higher swelling ratio was seen compared to PLGA-collagen/ PLGA-PEG-PLGA nanocomposite hydrogel. In addition, PLGA-collagen hydrogels exhibited a higher swelling ratio than PLGA-PEG-PLGA and PLGA-collagen/ PLGA-PEG-PLGA hydrogels $(P<0.05)$. The incorporating of PLGAPEG-PLGA nanoparticles into the PLGA-collagen hydrogels reduced the swelling ratio of nanocomposite hydrogels.

\section{Degradation evaluation}

Most tissue engineering applications need a scaffold that stabilizes its structural and mechanical attributes for a long time to promote and support the growing tissues. The porous scaffold degradation rate affects cell vitality, cell growth, and the response of the host [46]. When the hydrogel is exposed to saline-buffered phosphate (PBS), water penetrates the hydrogel matrix resulting in random ester bond hydrolysis and a decrease in molecular weight. The degradation mechanism of the hydrogels is an influential factor in determining the optimal release of the active agent in actual conditions [47]. Figure 5B shows weight loss graph of prepared hydrogels incubated over 21 days in $4 \mathrm{~mL}$ of PBS at pH 7.4. As evident from the figure, the weight losses of the hydrogels were rapid in the first 14 days.

PLGA could be decomposed by hydrolytic and enzymatic degradation [48]. The changes in PLGA properties during the biodegradation process have an impact on the degradation and release of bioactive agents incorporated. PLGA 's physical attributes are demonstrated to depend on several parameters, such as lactide to glycolide ratio, initial molecular weight, water exposure, and storage temperature [49]. Indeed, the degradation of the PLGA-PEG-PLGA hydrogels could be suitably controlled by changing the LA/GA and PEG/PLGA ratios [50]. However, PLGA-collagen /PLGA-PEG-PLGA scaffold weight loss was slower than the PLGA-collagen composite hydrogel. According to the graphs, PLGA-collagen /PLGA-PEG-PLGA scaffold weight loss dropped to 35.36 (wt/wt \%) by 7th day, to 45.83 (wt/wt \%) by 14th day, and finally to 50.82 (wt/wt \%) by 21 th day.

\section{Release study}

The release kinetics of TGF- $\beta 1$ depends on both the encapsulated solute nature and the microparticle structure, including copolymer composition, hydrophilicity, and molecular weight [51]. The TGF- $\beta 1$ release can be controlled by the copolymer matrix degradation rate [52]. The intention is to select the hydrogel system in such a way as to provide sufficient degradation time for the sustainable release of growth factors [53]. TGF- $\beta 1$ was encapsulated in PLGA-PEG-PLGA nanoparticles and released in a sustained 
manner within 21 days without remarkable initial burst release. The TGF- $\beta 1$ in vitro release from the PLGA-PEG-PLGA nanoparticles, PLGA-collagen hybrid scaffold, and PLGA-collagen/ PLGA-PEG-PLGA nanocomposite hydrogel matrix was monitored within 21 days, and confirmed by ELISA. As seen in Fig. $5 \mathrm{C}$, the release profile shows the initial burst release during the first 48 hours for all three types of hydrogels. This slope is sharper for PLGA-collagen due to its more degradability profile. The release of TGF- $\beta 1$ gradually increased to 2 weeks in a relatively constant manner. This behavior indicates that the growth factor has been effectively encapsulated in the hydrogels 3D-strucutures and its release depends on the copolymer's degradation over time. The most important factor in the release process of the TGF- $\beta 1$ during the 14 to 21 days is copolymers degradation features. The PLGA-PEG-PLGA copolymer ELISA results indicated that the burst release of TGF- $\beta 1$ occurs during the first 48 hours is related to the growth factor desorption at the surface of nanoparticles. Although this burst-release effect appears to be more significant, the final cumulative release after 21 days was 78 percent, indicating a longer time period for TGF- $\beta 1$ release. At the end of the test duration, the cumulative percentages of TGF- $\beta 1$ releases for PLGAcollagen and PLGA-collagen/PLGA-PEG-PLGA were 85 percent, and 73 percent, respectively. This observation demonstrates that the growth factor encapsulation process was efficiently done.

Nevertheless, approximately $30 \%$ of the TGF- $\beta 1$ was enzymatically or chemically degraded. Our findings indicate that PLGA-PEG 1500 -PLGA hydrogel with a molar ratio of (LA/GA: 2.4/1) is an appropriate nanoparticle system capable of releasing TGF- $\beta 1$ in a sustainable manner.

\section{Mechanical properties}

In order to reach a functional implant for any tissue-engineered construct, it is imperative to determine the material properties and compare them with the natural cartilage properties [54,55]. Natural-based hydrogels generally have lower mechanical performance than synthetic counterparts [56]. Synthetic polymers are integrated to improve the hydrogel's mechanical properties [57]. To successfully design systems in tissue engineering, it is fundamental to have a thorough understanding of biomaterials' function.

As a standard method for evaluating the mechanical strength of scaffolds, the scaffolds were subjected to compressive testing. Mechanical features of the PLGA-collagen and PLGA-collagen/PLGA-PEG-PLGA scaffolds in a wet state were examined to determine the adequacy of Young's modulus. Figure 6 shows the scaffolds ' compressive stress-strain curves. Our findings showed that Young's modulus of the PLGAcollagen hydrogels was improved by incorporating PLGA-PEG-PLGA nanoparticles and decreasing the porosity of the structure (about 2-fold). Nanocomposite biomaterials offer excellent mechanical features and higher strength [58].

Mechanical parameters data of the PLGA-collagen and PLGA-collagen/ PLGA-PEG-PLGA scaffolds are represented in Table 4. The enhanced tensile strength of PLGA-collagen/ PLGA-PEG-PLGA is likely due to the incorporation of the PLGA-PEG-PLGA nanoparticles. They increased the Young modulus by filling the void spaces of PLGA-collagen the porous scaffold. 
Table 4

Physiochemical properties of scaffolds. Values are mean \pm standard $(n=3)$.

\begin{tabular}{|llll|}
\hline & collagen & PLGA-collagen & $\begin{array}{l}\text { PLGA-collagen/PLGA- } \\
\text { PEG-PLGA }\end{array}$ \\
\hline Pore size $(\mu \mathrm{m})$ & $\begin{array}{l}187.36 \pm \\
15.38\end{array}$ & $133.32 \pm 45.16$ & $100.118 \pm 75.46$ \\
\hline Porosity \% & $\begin{array}{l}80.02 .1 \pm \\
0.41\end{array}$ & $61.33 \pm 0.32$ & $42.66 \pm 0.12$ \\
\hline Density $\left(\mathrm{g} / \mathrm{cm}^{3}\right)$ & $\begin{array}{l}0.090 \pm \\
0.03\end{array}$ & $0.135 \pm 0.01$ & $0.184 \pm 0.01$ \\
$\begin{array}{l}\text { Young's modulus } \\
\text { (MP) }\end{array}$ & - & 0.58 & 0.81 \\
\hline $\begin{array}{l}\text { Ultimate Tensile } \\
\text { Strength }(\mathrm{MP})\end{array}$ & - & 2.21 & 4.60 \\
\hline
\end{tabular}

\section{BET analysis}

The BET approach is employed to measure the specific surface area (SSA) of porous substances. This method is based on the measurement of $\mathrm{N}_{2}$ gas absorbed and desorbed at constant liquid nitrogen temperature by the surface material.

The $\mathrm{N}_{2}$ adsorption/desorption isotherms of PLGA-collagen/PLGA-PEG-PLGA-TGF $\beta 1$ and PLGA-collagen composites at 77K are demonstrated in Fig. 1 supplementary. These isotherms describe the information about the structure of porous scaffolds. According to the classifications of the IUPAC guidelines, the corresponding PLGA-collagen and PLGA-collagen/ PLGA-PEG-PLGA-TGF $\beta 1$ isotherms revealed type H3 hysteresis loops, indicating that the structure of the voids is comparable to cones [59]. The relative BET analysis parameters are categorized in Table 5 . The BET-specific surface area value (SBET $(\mathrm{m} 2 / \mathrm{g})$ ) for PLGA-collagen/PLGA-PEG-PLGA-TGFß1 nanocomposite hydrogel was discovered to be heightened compared with that of PLGA-collagen composite. The embedding of PLGA-PEG-PLGA nanoparticles into the PLGA-collagen network directed a reduction in total pore and volume pore diameter. 
Table 5

$\mathrm{S}_{\mathrm{BET}}$ and pore structure results of the PLGA-collagen and PLGA-collagen/PLGA-PEG-PLGA-

TGF $\beta 1$ composites.

\begin{tabular}{|lll|}
\hline Scaffold & PLGA-collagen & PLGA-collagen/PLGA-PEG-PLGA-TGF $\beta 1$ \\
\hline $\mathrm{S}_{\mathrm{BET}}\left(\mathrm{m}^{2} / \mathrm{g}\right)$ & 2.85 & 3.03 \\
\hline $\mathrm{V}_{\text {micro }}\left(\mathrm{cm}^{3} / \mathrm{g}\right)$ & 0.483 & 0.6969 \\
\hline Total pore volume $\left(\mathrm{cm}^{3} / \mathrm{g}\right)$ & 0.024 & 0.012 \\
\hline average pore diameter $(\mathrm{nm})$ & 24.22 & 4.2272 \\
\hline
\end{tabular}

\section{Cell viability}

The MTT assay is employed to verify the biocompatibility of the scaffolds. In this regard, the effects of the prepared samples on cellular viability and cell proliferation were studied by MTT.

Figure 7 manifests the viability of hDPSCs at time intervals of 3, 7, and 14 days. The control group was hDPSCs, cultured on tissue cell culture plates with DMEM minus scaffolds. The viability and cell proliferation increased significantly in all tested samples over 14 days. All prepared scaffolds resulted in the proliferation and suitable cell viability of h-DPSCs compared to the control group. The heightened cell viability was seen in PLGA-collagen/ PLGA-PEG-PLGA-TGF 31 scaffolds than in controls and nanocomposite hydrogels with free TGF- $\beta 1(p<0.05)$. This could be due to better cell attachment, presence of TGF- $\beta 1$, and sustained release of this growth factor over 14 days. The remarkable point is that cell proliferation was not stopped during the 14 days in all the scaffolds. The results confirmed all the scaffolds can be considered to be biocompatible with hDPSCc.

\section{Cell adhesion study}

The cellular adhesion is imperative for the proper synthesis of ECM for cartilage restoration. The cell-tocell associations verified the compatibility of the produced scaffolds in simulating ECM for the dynamics of cells [60]. To this end, SEM was used to confirm the adhesion of hDPSCs to the porous PLGA-collagen and PLGA-collagen/PLGA-PEG-PLGA-TGF $\beta 1$ hydrogels at 14th days of culture. As visible in the FESEM images (Fig. 8), throughout the PLGA-collagen/PLGA-PEG-PLGA, cells have well adhered with a spindlelike shape, both the surface and the pores, distributed evenly throughout the scaffold, indicating an appropriate proliferative condition. The pores of scaffolds are also filled with cells.

\section{Alcian blue staining}

Chondrogenic differentiation of hDPSCs may be characteristic of the formation of cartilage-like tissue through the secretion of GAG and type II collagen macromolecules in the ECM. The accumulation of GAG and type II collagen in PLGA collagen/ PLGA-PEG-PLGA-TGF- $\beta 1$ was visualized by Alcian blue staining at 14 days after cell seeding. Collagen scaffolds did not show expression of GAG and II type collagen. 
PLGA-collagen showed lower expression than the nanocomposite hydrogel. As manifested in Fig. 9A, improved GAG production in the ECM was observed throughout the PLGA-collagen, and PLGA collagen/PLGA-PEG-PLGA nanocomposite hydrogels, which were identified by producing an intense blue color.

\section{Gene expression experiments}

Real-time quantitative PCR (RT - PCR) was accomplished to ascertain the effects of the scaffolds composition as well as TGF- $\beta 1$ on differentiation of hDPSCs during 21 days of cell culture. A positive effect of TGF- $\beta 1$ on chondrogenesis has been established in many reports [61, 62]. Aggrecan, Type II collagen, and Sox-9 determined the chondrogenic differentiation of DPSCs. The mRNA level pattern for all three genes was similar throughout the PCR assay.

hDPSCs seeded on PLGA-collagen/PLGA-PEG-PLGA-TGF- $\beta 1$ hydrogels displayed the most increased expression in all three genes. As seen in Fig. 9B, growing trends in gene expression were higher in PLGAcollagen / PLGA-PEG-PLGA - TGF- $\beta 1$ scaffold (4.1-fold) than the collagen scaffold (1.24-fold) (P $\leq 0.001)$ and PLGA-collagen (2.28-fold) $(\mathrm{P} \leq 0.05)$. This matter is being proved by the TGF- $\beta 1$ effect on hDPSCs chondrogenic differentiation capacity.

According to gene expression data, PLGA-collagen/PLGA-PEG-PLGA-TGF- $\beta 1$ hydrogel can be regarded as a promising matrix and delivery vehicle for the controlled release of TGF- $\beta 1$ to promote advancement in articular cartilage defect sites.

\section{Conclusion}

Molecules encapsulation technology for locally growth factor release is a promising strategy for establishing a sustained delivery system useful for either drug delivery or tissue engineering purposes. Another attractive aspect of encapsulation is the protection of growth factors from early enzymatically or chemically degradation in physiological conditions. Implantable or biomaterials are good depot systems for pre-programmed release and sustained release of tissue growth factors. Tissue engineering techniques with a combination of 3D biomimetic systems and the sustained release of therapeutic agents represent technological advancements for cell therapy studies. It is the first time to report the nanocomposite scaffold comprising PLGA-collagen and PLGA-PEG-PLGA nanoparticles supplemented by TGF- $\beta 1$ for enhancing DPSCs chondrogenic differentiation. PLGA-collagen/PLGA-PEG-PLGA nanocomposite scaffolds caused the proliferation of hDPSCs and TGF- $\beta 1$ promoted differentiation of hDPSCs at the same time.

The results of the adhesion and MTT tests proved that the most significant feature of our research is that the scaffolds produced are biocompatible. The SEM observations demonstrated the compatibility and adhesive capability of our scaffolds for the h-DPSC, and their potential to promote appropriate cell growth that could be advantageous in applications for cartilage tissue engineering. According to the RTPCR results, ECM components production, such as aggrecan, collagen type II, and Sox-9 were verified to 
be comparable to those in the native cartilage tissue. The PLGA-collagen / PLGA-PEG-PLGA nanocomposite scaffold, in addition to maintaining the required biological properties, also has acceptable mechanical properties.

Altogether, the principal goal of this project was to discover the chondrogenesis potential of PLGAcollagen/PLGA-PEG-PLGA hydrogels supplemented with TGF- $\beta 1$ growth factor. The achieved nanocomposite hydrogel merits additional in-vivo research to have the prospect for use in cartilage tissue restoration.

\section{Abbreviations}

PBS: phosphate-buffered saline

FBS: fetal bovine serum

DMEM: Dulbecco Modified Eagle's Medium

h-DPSCs: human dental pulp-derived mesenchymal stem cells

ELISA: enzyme-linked immunosorbent assay

PLGA-PEG-PLGA: poly D, L (lactide-co-glycolide) -b- poly (ethylene glycol)-b- poly D, L (lactide-co-glycolide MTT: 3-(4,5-dimethylthiazol-2-yl)-2,5-diphenyltetrazolium bromide

\section{Declarations}

\section{o Ethics approval and consent to participate:}

Not applicable.

\section{o Consent for publication:}

All authors have been personally and actively involved in substantial work leading to the paper, and will take public responsibility for its content.

\section{o Availability of data and materials:}

The datasets generated during and/or analyzed during the current study are available from the corresponding author on reasonable request.

\section{o Competing interests:}

There is no competeing interest. 


\section{o Funding}

This investigation was funded by a grant from Tabriz University of Medical Sciences, Tabriz, Iran, Grant No: 64103.

\section{o Authors' contributions:}

Parisa Ghandforoushan: Conceptualization, Methodology, Software, Investigation, Writing- Original; Jalal Hanaee: Validation, Supervision; Zahra Aghazadeh: Methodology, Validation, Data Curation; Shahin Ahmadian: Conceptualization, Methodology; Mohammad Samiei: Data Curation, Validation; Amir Mohammad Navali: Investigation, Writing- Reviewing and Editing; Ali khatibi: Investigation, Software, Data Curation; Soodabeh Davaran: Conceptualization, Methodology, Validation, Supervision.

\section{o Acknowledgements}

This project was fulfilled at the Stem Cell Research Center, Tabriz, Iran. The authors would like to thank everybody who assisted us in this regard.

\section{o Authors' information}

Not applicable.

\section{References}

1. Elisseeff J. Injectable cartilage tissue engineering. Expert Opin Biol Ther. 2004;4(12):1849-59.

2. Kalamegam G, et al., A Comprehensive Review of Stem Cells for Cartilage Regeneration in Osteoarthritis. 2018.

3. Iturriaga $L$, et al. Advances in stem cell therapy for cartilage regeneration in osteoarthritis. Expert Opin Biol Ther. 2018;18(8):883-96.

4. Amini AA, Nair LS. Injectable hydrogels for bone and cartilage repair. Biomed Mater. 2012;7(2):024105.

5. Munir N, Callanan A. Novel phase separated polycaprolactone/collagen scaffolds for cartilage tissue engineering. Biomed Mater. 2018;13(5):051001.

6. Mistry $\mathrm{H}$, et al., Autologous chondrocyte implantation in the knee: systematic review and economic evaluation. 2017.

7. Demoor $\mathrm{M}$, et al. Cartilage tissue engineering: Molecular control of chondrocyte differentiation for proper cartilage matrix reconstruction. Biochim et Biophys Acta (BBA) - Gen Subj. 2014;1840(8):2414-40.

8. Mansour JM, Biomechanics of cartilage. Kinesiology: the mechanics and pathomechanics of human movement, 2003: p. 66-79. 
9. Sophia Fox AJ, Bedi A, Rodeo SA. The basic science of articular cartilage: structure, composition, and function. Sports health. 2009;1(6):461-8.

10. Fernandes TL, et al. Systematic review of human dental pulp stem cells for cartilage regeneration. Tissue Eng Part B: Reviews. 2020;26(1):1-12.

11. Li P-L, et al. Clinical-grade human dental pulp stem cells suppressed the activation of osteoarthritic macrophages and attenuated cartilaginous damage in a rabbit osteoarthritis model. Stem Cell Res Ther. 2021;12(1):1-15.

12. Hokmabad VR, et al. A Comparison of the Effects of Silica and Hydroxyapatite Nanoparticles on Poly ( $\varepsilon$-caprolactone)-Poly (ethylene glycol)-Poly ( $\varepsilon$-caprolactone)/Chitosan Nanofibrous Scaffolds for Bone Tissue Engineering. Tissue Eng Regenerative Med. 2018;15(6):735-50.

13. Aghazadeh M, et al. The Effect of Melanocyte Stimulating Hormone and Hydroxyapatite on Osteogenesis in Pulp Stem Cells of Human Teeth Transferred into Polyester Scaffolds. Fibers Polym. 2018;19(11):2245-53.

14. Cristaldi $M$, et al. Dental pulp stem cells for bone tissue engineering: a review of the current literature and a look to the future. Regen Med. 2018;13(2):207-18.

15. Williams DF, Chap. 36 - Hydrogels in Regenerative Medicine, in Principles of Regenerative Medicine (Third Edition), A. Atala, et al., Editors. 2019, Academic Press: Boston. p. 627-650.

16. Yegappan $\mathrm{R}$, et al. Injectable angiogenic and osteogenic carrageenan nanocomposite hydrogel for bone tissue engineering. Int J Biol Macromol. 2019;122:320-8.

17. Vega SL, Kwon MY, Burdick JA. Recent advances in hydrogels for cartilage tissue engineering. Eur Cells Mater. 2017;33:59.

18. Bernhard JC, Vunjak-Novakovic G. Should we use cells, biomaterials, or tissue engineering for cartilage regeneration? Stem Cell Res Ther. 2016;7(1):56.

19. Elango J, et al. Rheological, biocompatibility and osteogenesis assessment of fish collagen scaffold for bone tissue engineering. Int J Biol Macromol. 2016;91:51-9.

20. Lee HJ, Hybrid Hydrogels for Tissue Engineering. 2015.

21. Wang J, et al. Silk fibroin/collagen/hyaluronic acid scaffold incorporating pilose antler polypeptides microspheres for cartilage tissue engineering. Mater Sci Engineering: C. 2019;94:35-44.

22. Chicatun F, et al. Collagen/chitosan composite scaffolds for bone and cartilage tissue engineering, in Biomedical Composites. Elsevier; 2017. pp. 163-98.

23. Quinlan E, et al. Hypoxia-mimicking bioactive glass/collagen glycosaminoglycan composite scaffolds to enhance angiogenesis and bone repair. Biomaterials. 2015;52:358-66.

24. Raeisdasteh Hokmabad V, et al. Design and fabrication of porous biodegradable scaffolds: a strategy for tissue engineering. J Biomater Sci Polym Ed. 2017;28(16):1797-825.

25. Khorshid NK, et al. Novel Structural Changes during Temperature-Induced Self-Assembling and Gelation of PLGA-PEG-PLGA Triblock Copolymer in Aqueous Solutions. Macromol Biosci. 2016;16(12):1838-52. 
26. Rong $X$, et al. Neuroprotective effect of insulin-loaded chitosan nanoparticles/PLGA-PEG-PLGA hydrogel on diabetic retinopathy in rats. Int J Nanomed. 2019;14:45.

27. Pan J, et al. Thermosensitive hydrogel delivery of human periodontal stem cells overexpressing platelet-derived growth factor-BB enhances alveolar bone defect repair. Stem Cells Dev. 2019;28(24):1620-31.

28. Kirby GT, et al. Microparticles for sustained growth factor delivery in the regeneration of criticallysized segmental tibial bone defects. Materials. 2016;9(4):259.

29. Chen G, Kawazoe N, Porous scaffolds for regeneration of cartilage, bone and osteochondral tissue. Osteochondral Tissue Engineering: Nanotechnology, Scaffolding-Related Developments and Translation, 2018: p. 171-191.

30. Della Porta G, Ciardulli MC, Maffulli N. Microcapsule Technology for Controlled Growth Factor Release in Musculoskeletal Tissue Engineering. Sports Med Arthrosc Rev. 2018;26(2):e2-9.

31. Awad HA, et al. Effects of transforming growth factor $\beta 1$ and dexamethasone on the growth and chondrogenic differentiation of adipose-derived stromal cells. Tissue Eng. 2003;9(6):1301-12.

32. Na K, et al. Delivery of dexamethasone, ascorbate, and growth factor (TGF $\beta-3$ ) in thermo-reversible hydrogel constructs embedded with rabbit chondrocytes. Biomaterials. 2006;27(35):5951-7.

33. Askari $M$, et al. Sustained release of TGF- $\beta 1$ via genetically-modified cells induces the chondrogenic differentiation of mesenchymal stem cells encapsulated in alginate sulfate hydrogels. $J$ Mater Science: Mater Med. 2019;30(1):7.

34. Ghandforoushan P, et al., Novel nanocomposite scaffold based on Gelatin/PLGA-PEG-PLGA hydrogels embedded with TGF- $\beta 1$ for chondrogenic differentiation of human dental pulp stem cells in vitro. International Journal of Biological Macromolecules, 2022.

35. Hutmacher DW. Scaffolds in tissue engineering bone and cartilage, The Biomaterials: Silver Jubilee Compendium, D.F. Williams, Editor. 2000, Elsevier Science: Oxford. pp. 175-89.

36. Lee $\mathrm{DH}$, et al. Enhanced osteogenesis of $\beta$-tricalcium phosphate reinforced silk fibroin scaffold for bone tissue biofabrication. Int J Biol Macromol. 2017;95:14-23.

37. Zijah V, et al., Towards optimization of odonto/osteogenic bioengineering: in vitro comparison of simvastatin, sodium fluoride, melanocyte-stimulating hormone. In Vitro Cellular \& Developmental Biology-Animal, 2017. 53(6): p. 502-512.

38. Sun X, et al., Collagen-based porous scaffolds containing PLGA microspheres for controlled kartogenin release in cartilage tissue engineering. Artificial cells, nanomedicine, and biotechnology, 2018. 46(8): p. 1957-1966.

39. Valipour F, et al. Novel hybrid polyester-polyacrylate hydrogels enriched with platelet-derived growth factor for chondrogenic differentiation of adipose-derived mesenchymal stem cells in vitro. J Biol Eng. 2021;15(1):1-14.

40. Riaz T, et al. FTIR analysis of natural and synthetic collagen. Appl Spectrosc Rev. 2018;53(9):70346. 
41. Bhardwaj N, et al. Potential of 3-D tissue constructs engineered from bovine chondrocytes/silk fibroin-chitosan for in vitro cartilage tissue engineering. Biomaterials. 2011;32(25):5773-81.

42. Khajavi M, et al., Fish cartilage: A promising source of biomaterial for biological scaffold fabrication in cartilage tissue engineering. Journal of Biomedical Materials Research Part A, 2021.

43. Song JE, et al. Evaluation of silymarin/duck's feet-derived collagen/hydroxyapatite sponges for bone tissue regeneration. Mater Sci Engineering: C. 2019;97:347-55.

44. Karageorgiou V, Kaplan D. Porosity of 3D biomaterial scaffolds and osteogenesis. Biomaterials. 2005;26(27):5474-91.

45. Wang $Y-F$, et al. Systematic characterization of porosity and mass transport and mechanical properties of porous polyurethane scaffolds. J Mech Behav Biomed Mater. 2017;65:657-64.

46. She Z, et al. Preparation and in vitro degradation of porous three-dimensional silk fibroin/chitosan scaffold. Polym Degrad Stab. 2008;93(7):1316-22.

47. Rychter P, et al. PLGA-PEG terpolymers as a carriers of bioactive agents, influence of PEG blocks content on degradation and release of herbicides into soil. Polymer Degradation and Stability; 2019.

48. Makadia HK, Siegel SJ. Poly lactic-co-glycolic acid (PLGA) as biodegradable controlled drug delivery carrier. Polymers. 2011;3(3):1377-97.

49. Houchin M, Topp E. Physical properties of PLGA films during polymer degradation. J Appl Polym Sci. 2009;114(5):2848-54.

50. Li Y, Rodrigues J, Tomas H. Injectable and biodegradable hydrogels: gelation, biodegradation and biomedical applications. Chem Soc Rev. 2012;41(6):2193-221.

51. Li Y, et al. Immunosuppressive PLGA TGF- $\beta 1$ Microparticles Induce Polyclonal and Antigen-Specific Regulatory T Cells for Local Immunomodulation of Allogeneic Islet Transplants. Front Immunol. 2021;12:1484.

52. Chen $\mathrm{L}$, et al. Growth factor and its polymer scaffold-based delivery system for cartilage tissue engineering. Int J Nanomed. 2020;15:6097.

53. Lin SJ, et al. Growth factor-loaded microspheres in mPEG-polypeptide hydrogel system for articular cartilage repair. J Biomedical Mater Res Part A. 2021;109(12):2516-26.

54. Gan S, et al. Nano-hydroxyapatite enhanced double network hydrogels with excellent mechanical properties for potential application in cartilage repair. Carbohydr Polym. 2020;229:115523.

55. Ma F, et al. In situ fabrication of a composite hydrogel with tunable mechanical properties for cartilage tissue engineering. J Mater Chem B. 2019;7(15):2463-73.

56. Mallakpour S, Tukhani M, Hussain CM. Recent advancements in 3D bioprinting technology of carboxymethyl cellulose-based hydrogels: Utilization in tissue engineering. Adv Colloid Interface Sci. 2021;292:102415.

57. Khalesi $\mathrm{H}$, et al., New insights into food hydrogels with reinforced mechanical properties: A review on innovative strategies. Advances in Colloid and Interface Science, 2020: p. 102278. 
58. Mondal D, Willett TL. Mechanical properties of nanocomposite biomaterials improved by extrusion during direct ink writing. J Mech Behav Biomed Mater. 2020;104:103653.

59. Czepirski L, Balys MR, Komorowska-Czepirska E. Some generalization of Langmuir adsorption isotherm. Internet J Chem. 2000;3(14):1099-8292.

60. Chi $\mathrm{H}$, et al. 3D-HA scaffold functionalized by extracellular matrix of stem cells promotes bone repair. Int J Nanomed. 2020;15:5825.

61. Ying J, et al. Transforming growth factor-beta1 promotes articular cartilage repair through canonical Smad and Hippo pathways in bone mesenchymal stem cells. Life Sci. 2018;192:84-90.

62. Asen A-K, et al. Sustained spatiotemporal release of TGF- $\beta 1$ confers enhanced very early chondrogenic differentiation during osteochondral repair in specific topographic patterns. FASEB J. 2018;32(10):5298-311.

\section{Figures}

A
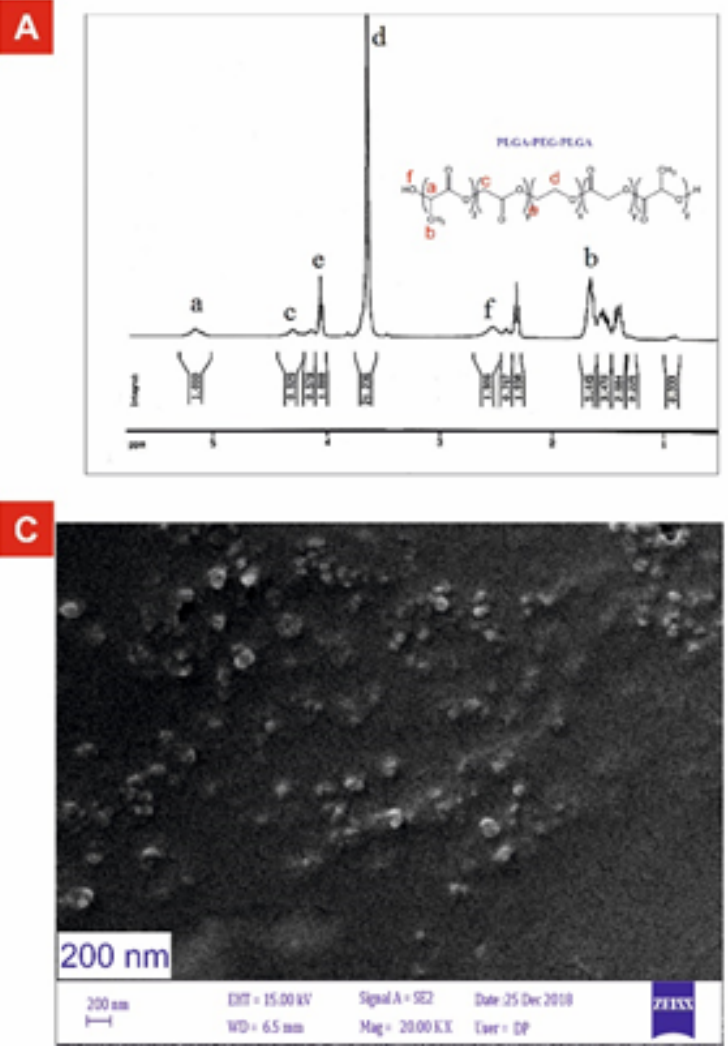

B

PLGA-PEG-PLGA

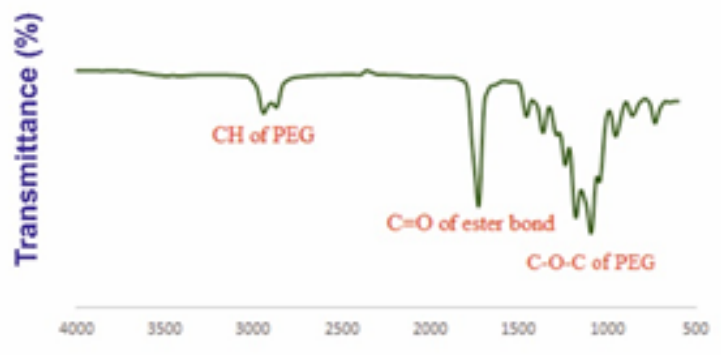

Wavenumber $\mathrm{cm}-1$

D

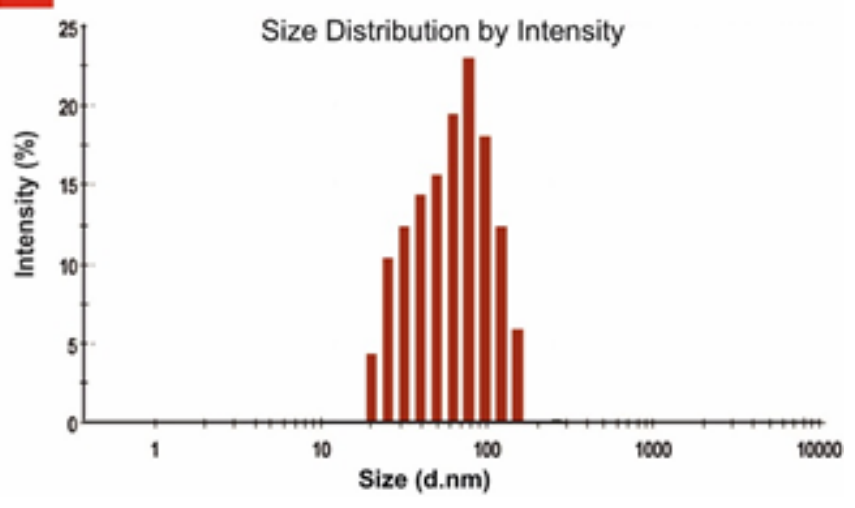

Figure 1

PLGA-PEG-PLGA nanoparticles characterizations ; A) ${ }^{1} \mathrm{H}-\mathrm{NMR}$ spectrum of PLGA-PEG-PLGA nanoparticles. B) FT-IR analysis of PLGA-PEG-PLGA nanoparticles in $\mathrm{CDCl}_{3}$. C) The SEM image of PLGAPEG-PLGA nanoparticles. D) Dynamic light scattering (DLS) result for particle size distribution of the PLGA-PEG-PLGA nanoparticles. 

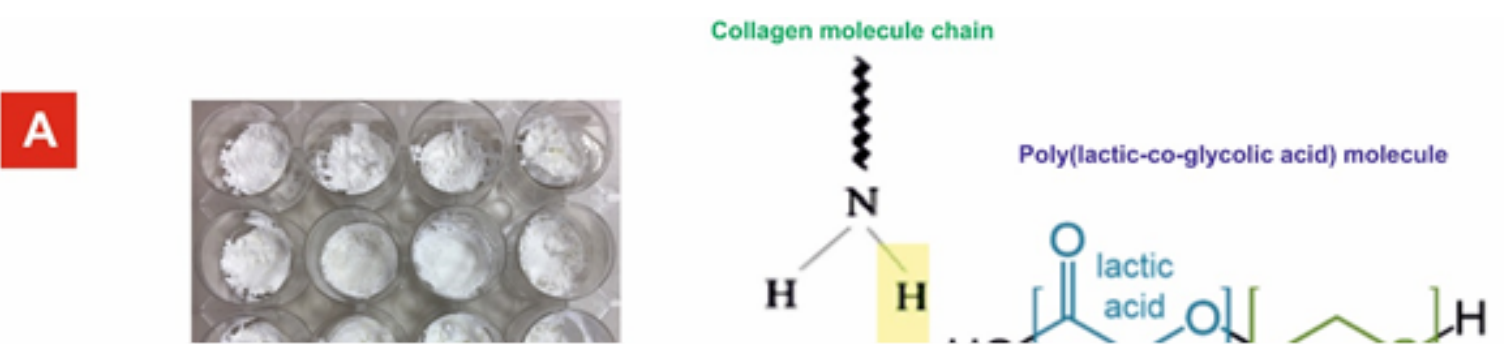

Figure 2

A) PLGA-collagen scaffold, synthetized by freeze- drying method. B) FTIR spectra of PLGA, PLGAcollagen-PLGA, and collagen. 


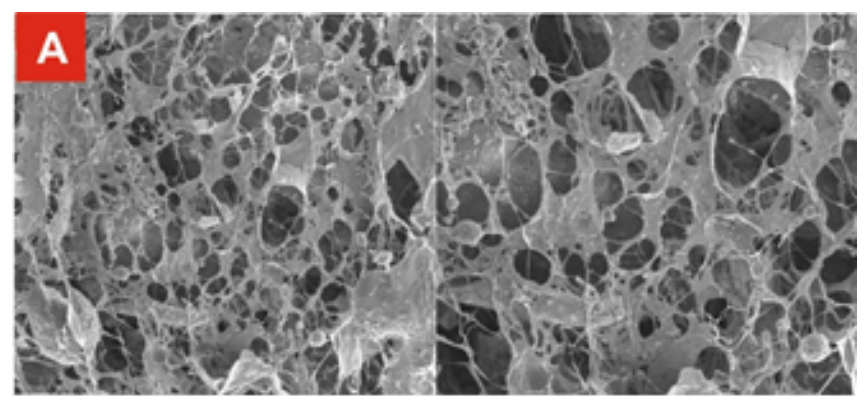

\section{Figure 3}

SEM images of (A) collagen, (B) PLGA-collagen, (C) PLGA-collagen/PLGA-PEG-PLGA scaffolds. D) Average pore size of Collagen, PLGA-collagen, and PLGA-collagen/PLGA-PEG-PLGA scaffolds determined by ImageJ. Results are presented as mean \pm standard deviation. 
A

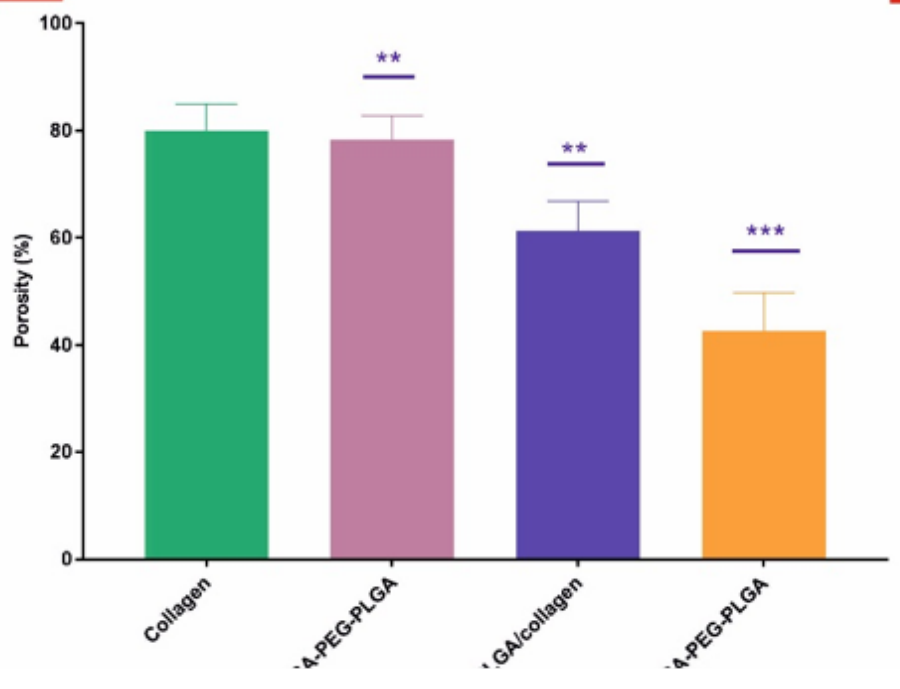

B

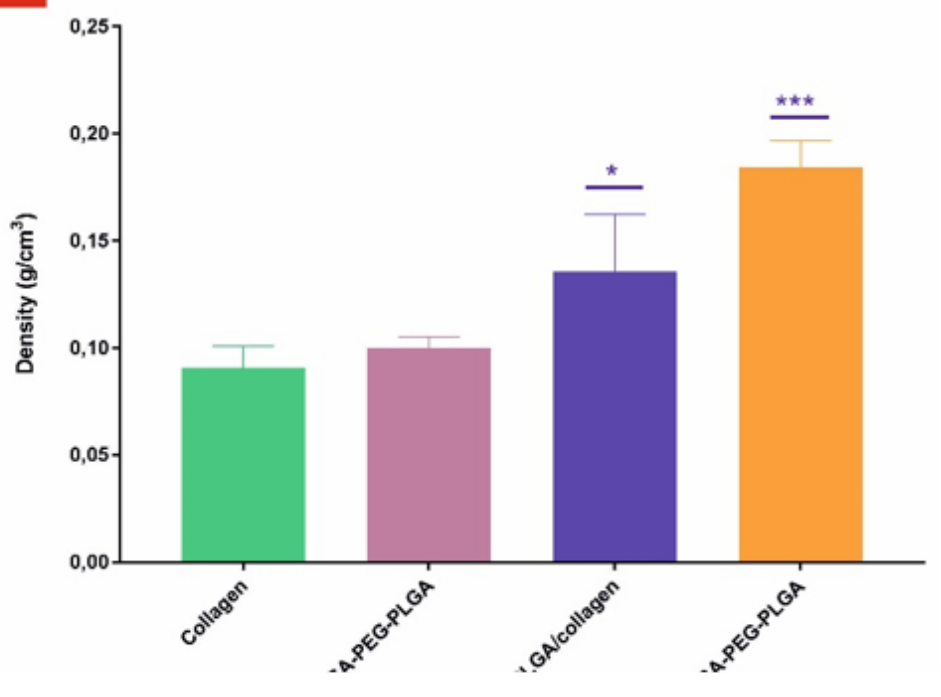

Figure 4

Porosity (A) and density (B) of the collagen, PLGA-PEG-PLGA, PLGA-collagen, and PLGA-collagen/PLGAPEG-PLGA scaffolds. $\left({ }^{*} p<0.05,{ }^{* *} p<0.01\right.$, and $\left.{ }^{* \star *} p<0.001\right)$. 
A

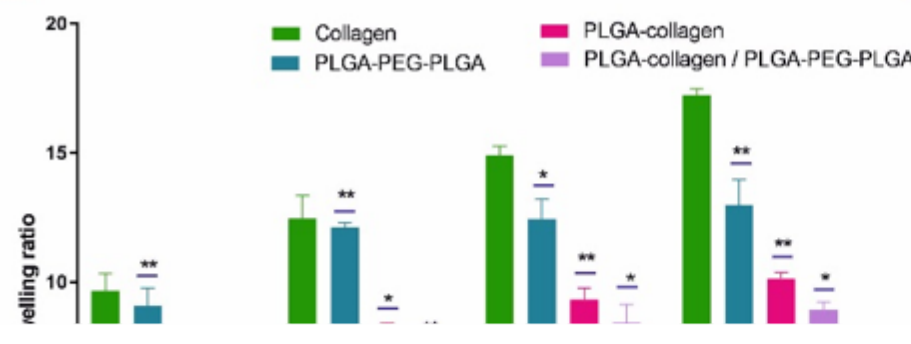

B

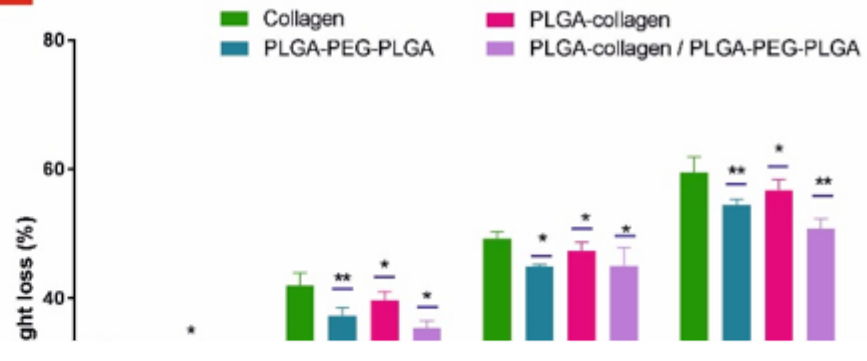

\section{Figure 5}

A) Swelling behavior of the collagen, PLGA-PEG-PLGA, PLGA-collagen, and PLGA-collagen/PLGA-PEGPLGA scaffolds in PBS (at $\left.\mathrm{pH}=7.4,37^{\circ} \mathrm{C}\right)$, ( ${ }^{*} \mathrm{p}<0.05$ and $\left.{ }^{* *} \mathrm{p}<0.01\right)$ during $96 \mathrm{~h}$. ( ${ }^{*} \mathrm{p}<0.05$ and $\left.\left.{ }^{* *} \mathrm{p}<0.01\right) . \mathrm{B}\right)$ The degradation graph of the collagen, PLGA-PEG-PLGA, PLGA-collagen, and PLGA-collagen/PLGA-PEGPLGA scaffolds in 21 days. The medium was replaced with a fresh medium every 4 days. The degradation process was fulfilled at $37^{\circ} \mathrm{C}$. C) In vitro release profile of TGF- $\beta 1$ from PLGA-collagen, PLGAPEG-PLGA, and PLGA-collagen/PLGA-PEG-PLGA scaffolds delivery systems as determined by ELISA assay. Data are expressed as mean \pm standard deviation $(n=3)$. 

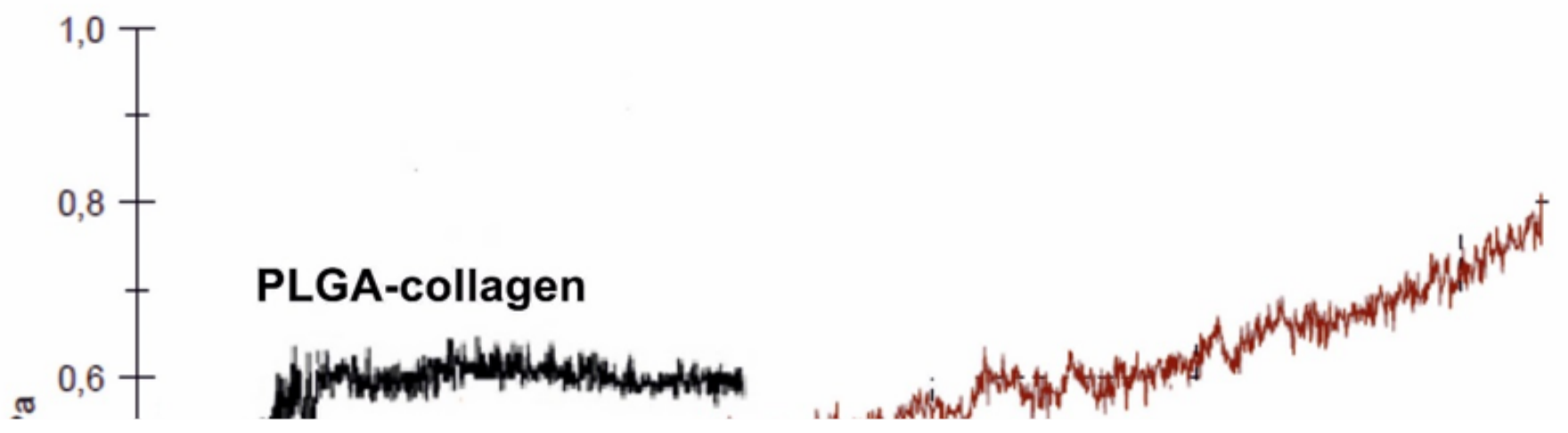

Figure 6

The stress-strain curves of PLGA-collagen and PLGA-collagen /PLGA-PEG-PLGA-TGF- $\beta 1$ hydrogels in wet conditions. Data are expressed as mean \pm standard deviation $(n=3)$. 


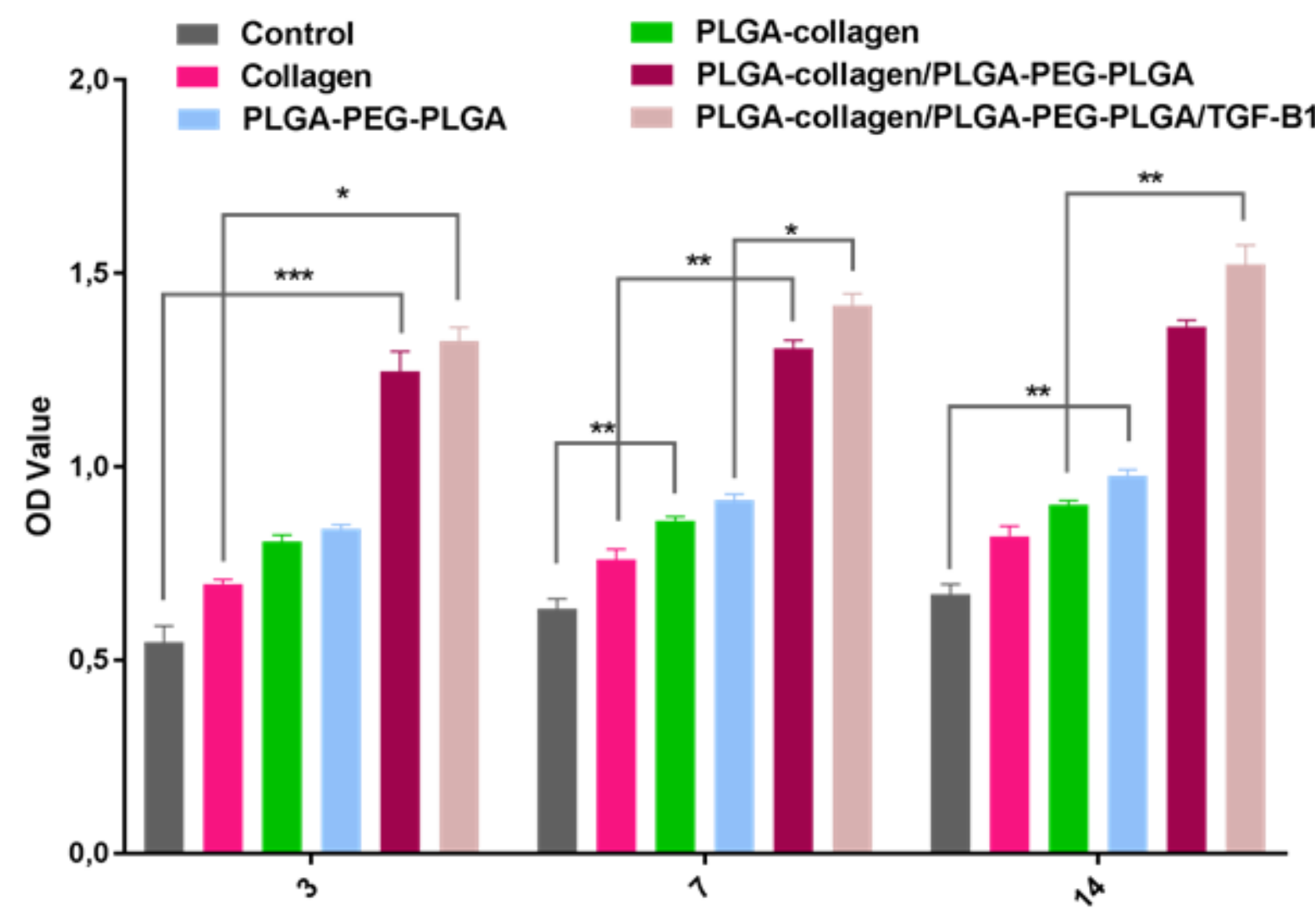

Days

Figure 7

MTT assay for hDPSCs cultured on the routine medium (control), collagen, PLGA-PEG-PLGA, PLGAcollagen, PLGA-collagen/PLGA-PEG-PLGA, and PLGA-collagen/PLGA-PEG-PLGA-TGF- $\beta 1$ hydrogels for 3, 7, and 14 days. $\left({ }^{*} p<0.05, * * p<0.01\right.$, and $\left.{ }^{* * *} p<0.001\right)$. 


\section{Figure 8}

Scanning electron microscopy (SEM) images of hDPSCs following 14 days of culture throughout the PLGA-collagen/PLGA-PEG-PLGA hydrogels, ((A; $20 \mu \mathrm{m}, \mathrm{B} ; 50 \mu \mathrm{m})$.

\section{Figure 9}

A) Histological analysis of the hydrogels by Alcian blue staining. B) The expression of chondrogenic marker genes aggrecan, Sox-9, and collagen type II in hDPSCs seeded on collagen, PLGA-collagen, PLGPEG-PLGA, PLGA-collagen /PLGA-PEG-PLGA, and PLGA-collagen /PLGA-PEG-PLGA/TGF- $\beta 1$ scaffolds within 3 weeks via real-time PCR. The genes were normalized to GAPDH $\left({ }^{\star} p<0.05\right.$, ${ }^{\star \star} p<0.01$, and ${ }^{\star \star \star} p<$ $0.001)$.

\section{Supplementary Files}

This is a list of supplementary files associated with this preprint. Click to download.

- GraphicalAbstract.png

- Supplemantaryfile.docx 